\title{
Affective regulation of cognitive-control adjustments in remitted depressive patients after acute tryptophan depletion
}

\author{
Henk van Steenbergen • Linda Booij • \\ Guido P. H. Band • Bernhard Hommel • \\ A. J. Willem van der Does
}

Published online: 6 January 2012

(C) The Author(s) 2012. This article is published with open access at Springerlink.com

\begin{abstract}
Negative affect in healthy populations regulates the appraisal of demanding situations, which tunes subsequent effort mobilization and adjustments in cognitive control. In the present study, we hypothesized that dysphoria in depressed individuals similarly modulates this adaptation, possibly through a neural mechanism involving serotonergic regulation. We tested the effect of dysphoria induced by acute tryptophan depletion (ATD) in remitted depressed patients on conflict adaptation in a Simon task. ATD temporarily lowers the availability of the serotonin precursor LTryptophan and is known to increase depressive symptoms
\end{abstract}

H. van Steenbergen $(\bowtie) \cdot$ G. P. H. Band · B. Hommel •

A. J. W. van der Does

Leiden University,

Wassenaarseweg 52 ,

2333 AK Leiden, The Netherlands

e-mail: HvanSteenbergen@fsw.leidenuniv.nl

H. van Steenbergen • G. P. H. Band • B. Hommel •

A. J. W. van der Does

Leiden Institute for Brain and Cognition,

Leiden, The Netherlands

L. Booij

Sainte-Justine Hospital Research Center,

Montreal, Québec, Canada

L. Booij

University of Montreal,

Montreal, Québec, Canada

L. Booij

McGill University,

Montreal, Québec, Canada

A. J. W. van der Does

Leiden University Medical Center,

Leiden, The Netherlands in approximately half of remitted depressed participants. We found that depressive symptoms induced by ATD were associated with increased conflict adaptation. Our finding extends recent observations implying an important role of affect in regulating conflict-driven cognitive control.

Keywords Acute tryptophan depletion - Affect - Cognitive conflict - Cognitive control · Conflict adaptation · Demand appraisal · Depression · Dysphoria · Effort mobilization . Mood $\cdot$ Serotonin

One of the defining symptoms of depression is a depressed mood. Although a depression is certainly undesirable and maladaptive, normal and pathological mood states of sadness lie on a continuum and may actually play an important role in adaptive behavior (e.g., Andrews \& Thomson, 2009; Mayberg et al., 1999). The mood-behavior model (MBM; Gendolla, 2000) proposes that negative affect helps to regulate resource mobilization and behavior via a biased appraisal of situational demands (cf. Ach, 1935; Hillgruber, 1912). Indeed, several studies using mood induction procedures in healthy populations have shown that negative affect increases demand appraisals of difficult situations, which improves subsequent effort mobilization as measured by cardiovascular adjustments (for a review, see Gendolla \& Brinkmann, 2005). Recent evidence suggests that behavioral adaptation to fluctuating task difficulty is also subject to this affective regulation. We have recently shown that dynamic behavioral adjustments after demanding conflict trials in a flanker task are stronger following the induction of a sad or anxious mood than following a happy or calm mood (van Steenbergen, Band, \& Hommel, 2010). These data suggest that negative affect may facilitate conflict-driven recruitment of cognitive control, as can be measured by trial-to-trial adaptations in 
conflict tasks that use randomized presentation of compatible and incompatible trials (Gratton, Coles, \& Donchin, 1992; for a review, see Egner, 2007).

In the present study, we hypothesized that - analogous to these negative mood effects in healthy samples - dysphoria in remitted depressed individuals may also improve demand-driven behavioral adaptation. Recent work has demonstrated enhanced demand-driven effort recruitment in depression using cardiovascular measures (Brinkmann \& Gendolla, 2007), but no study has yet demonstrated such effects of depressed mood on behavioral adjustments in cognitive control tasks. Note that the majority of past research on the link between depression and cognitive control has compared attentional interference effects only (i.e., calculating main compatibility effects, such as the Stroop effect) and has not addressed the modulation of trial-to-trial adaptations in control (i.e., a sequential modulation of interference effects). Although this literature has yielded some evidence for depression-related general deficits in cognitive control (for reviews, see Levin, Heller, Mohanty, Herrington, \& Miller, 2007; Rogers et al., 2004), it has been proposed that such deficits are mainly driven by factors other than mood statefor example, increased rumination (e.g., Nolen-Hoeksema, Wisco, \& Lyubomirsky, 2008; Philippot \& Brutoux, 2008). Mood induction studies in healthy populations actually support this suggestion, showing that sad mood in itself does not modulate effort mobilization or interference effects (Chepenik, Cornew, \& Farah, 2007; van Steenbergen et al., 2010). These findings are also consistent with the notion that a negative mood in itself does not have general motivational implications, but can regulate effort adaptation via modulated demand appraisals, thus producing context-sensitive effects in tasks using fluctuating task demands (Gendolla, 2000). Thus, in contrast with the analysis of main attentional interference effects, sequential effect analysis may provide a measure that is much more sensitive to depressed-mood modulation.

Modulation of demand-driven behavioral adaptation in depression may arise from the negativity bias and its associated amplified neural reactivity to adverse and demanding events typically observed in this disorder (Beck, 1976; Olvet \& Hajcak, 2008; Pizzagalli, Peccoralo, Davidson, \& Cohen, 2006). It has been proposed that these neural effects are driven by central serotonin (5-hydroxytryptamine; 5-HT) regulation (Cools, Roberts, \& Robbins, 2008; Jocham \& Ullsperger, 2009). The impact of central 5-HT on mood and cognition has been investigated with acute tryptophan depletion (ATD), a manipulation that temporarily lowers the availability of LTryptophan (Trp), the precursor of serotonin. ATD leads to a transient increase in depressed mood in individuals who are vulnerable to depression (e.g., former patients and first-degree relatives), but not in healthy nonvulnerable individuals (cf. Booij, van der Does, \& Riedel, 2003; Ruhe, Mason, \& Schene, 2007; van der Does, 2001). Some studies have shown that ATD can lower attentional interference independent of mood changes, that is, in both nonvulnerable and depressionvulnerable individuals (Booij et al., 2005b; Schmitt et al., 2000; for a review, see Mendelsohn, Riedel, \& Sambeth, 2009). However, it is still an open question whether ATDinduced mood changes may modulate conflict adaptation.

Recent neuroimaging studies have provided some initial support for an affective modulation of conflict adaptation (for reviews, see Evers, van der Veen, Fekkes, \& Jolles, 2007; Fusar-Poli et al., 2006). For example, ATD-induced depressed mood correlates with activity in the anterior cingulate cortex (ACC; Evers, van der Veen, Jolles, Deutz, \& Schmitt, 2009)a region playing a prominent role in the generation of adaptive control to demanding situations (Botvinick, Braver, Barch, Carter, \& Cohen, 2001). Accordingly, increased conflictrelated activity in the ACC may increase demand-driven behavioral adjustments (cf. Kerns et al., 2004; van Steenbergen et al., 2010). However, there is also evidence suggesting that individuals with Major Depressive Disorder (MDD) show hyperactivation in the ACC, which is associated with decreased postconflict adjustments (Meiran, Diamond, Todor, \& Nemets, 2011; Pizzagalli, 2011). Decreased conflict adaptation has also been observed when participants receive negative feedback concerning their task performance, an effect that is particularly strong in subclinically depressed participants (Holmes \& Pizzagalli, 2007). Moreover, serotonin polymorphisms related to depression have also been linked to decreases in postconflict behavioral adjustments (Holmes, Bogdan, \& Pizzagalli, 2010; Osinsky et al., 2009). Taken together, these findings suggest that the depressive symptoms can modulate conflict adaptation in either direction, possibly depending on the severity of the symptoms and the difficulty of the task (Gendolla, 2000; see the Discussion section). However, the role of 5-HT accounting for this link is not known yet.

In the present study, we investigated the putative link between conflict adaptation, 5-HT function, and depressed mood. Focusing on trial-to-trial adjustments in performance, we reanalyzed data from an earlier published ATD study (Booij et al., 2005b) that reported only overall responseconflict effects, as measured with a Simon task (Simon \& Rudell, 1967), in a group of remitted depressed patients after they received ATD. In that study, ATD increased depressive symptoms in about half of the investigated sample and thus provided an excellent design to investigate the associations between depressive symptoms, 5-HT, and conflict adaptation. Similar to the better known Stroop and flanker tasks, the Simon paradigm is a conflict-inducing task that requires speeded responses to targets that randomly appear in locations that correspond (compatible trial) or do not correspond (incompatible trial) to the location of the correct response key. Incompatible, demanding trials evoke response conflict, which is thought to generate increased cognitive control on subsequent trials (Botvinick et al., 2001). This 
adaptation to conflict is manifested by reduced compatibility effects in trials following conflict (incompatible) trials as compared with trials following nonconflict (compatible) trials (Gratton et al., 1992; for a review, see Egner, 2007). Given previous theory and evidence for enhanced demanddriven effort mobilization in dysphoria (Brinkmann \& Gendolla, 2007; Gendolla, 2000) and after negative mood inductions (Gendolla, 2000; van Steenbergen et al., 2010), and neural evidence suggesting potentiated conflict responses in individuals who show a depressed mood response to ATD (Evers et al., 2009), we may hypothesize that ATD increases conflict adaptation, especially in individuals in whom ATD transiently induces depressive symptoms. Conversely, it might also be possible that the ATD intervention in our remitted patients simply mimics (for a more complicated picture, see Evers et al., 2007) the more chronic impairments associated with MDD (Meiran et al., 2011; Pizzagalli, 2011) and related serotonin polymorphisms (Holmes et al., 2010; Osinsky et al., 2009), which would predict reduced conflict adaptation after ATD.

\section{Method}

Twenty-three patients were administered a high-dose and lowdose ATD mixture (100 vs. $25 \mathrm{~g}$ amino acids) in a double-blind randomized crossover design with two sessions, separated by at least 4 days (Booij et al., 2005b, c). The $100 \mathrm{~g}$ and $25 \mathrm{~g}$ ATD mixtures have previously been shown to lower plasma Trp levels by approximately $90 \%$ and $50 \%$, respectively, in this sample (Booij et al., 2005b) as well as in other samples (e.g., Booij, van der Does, Haffmans, \& Riedel, 2005a). The study was approved by an independent medical ethics committee (METIGG, Utrecht) and was performed according to their guidelines and regulations. All patients were informed about the study by their clinician and in detail by one of the investigators (L.B.), and provided written informed consent.

\section{Participants}

The sample has been described in detail previously (Booij et al., 2005b). Eligible patients were selected outpatients of a mood disorders clinic. Inclusion criteria were: age between 18 and 65 years; ongoing treatment with an SSRI or a serotonin noradrenaline reuptake inhibitor for at least 4 weeks, meeting DSM-IV criteria for depression in full or partial remission, and a Hamilton Depression Rating Scale (HRSD, 17 items) (Hamilton, 1960) lower than 15 (Frank et al., 1991). Exclusion criteria were: substance abuse within the past 3 months, psychosis (lifetime), major physical illness, lactation, and pregnancy. After excluding two drop-outs and two statistical outliers, 19 participants remained for statistical analyses (cf. Booij et al., 2005b).
Diagnoses and symptoms

As described in the original article (Booij et al., 2005b), depressive symptoms were assessed with the 10-item Montgomery Asberg Depression Rating Scale (MADRS) (Montgomery \& Asberg, 1979). The sleep items were omitted, since this could not change within an ATD session. Diagnoses, and demographic and clinical background variables were verified with the Structured Clinical Interview for DSM-IV (SCID-I) (First, Spitzer, Gibbon, \& Williams, 2005).

\section{Conflict adaptation}

The Simon task consisted of 64 trials presented in two consecutive blocks in which the stimulus interval differed (2,250 ms fixed vs. $2,250-5,500 \mathrm{~ms}$ variable; originally included to investigate a possible effect of task complexity). The word "left" or "right" was presented in randomized order either at the left or the right side of the screen. Participants were instructed to respond to the meaning of the word (target) - that is, making a left-hand response to the word "left" and a right-hand response to the word "right,"- and to ignore its location (distracter), as fast as possible. The same number of compatible (distracter location matches the target word) and incompatible (distracter location conflicts with the target word) stimuli was used. ${ }^{1}$

\section{Procedure}

Venous blood $(10 \mathrm{ml})$ was taken in the morning, $6 \mathrm{hr}$ after ATD and the next day $(t+24)$ and was analyzed for both total plasma Trp and the other large neutral amino acids (Fekkes, Vandalen, Edelman, \& Voskuilen, 1995). Mood was assessed $1 \mathrm{hr}$ before ATD $(\mathrm{t}-1), 6.5 \mathrm{hr}$ later $(\mathrm{t}+6.5)$, and the next morning $(t+24)$. The Simon task ("left/right task") was administered (Booij et al., 2005b) approximately $5.5 \mathrm{hr}$ after administration of the ATD mixture. The order of the low-dose session and the high-dose session was counterbalanced. Cognitive performance and mood was also assessed at a separate intake and a postintervention session. The average of these two assessments was taken as baseline measurement (cf. Booij et al., 2005b).

\section{Data analysis}

Repeated measures ANOVAs were used for sequential analysis of Simon performance, separately for correct reaction time

\footnotetext{
${ }^{1}$ Note that we use the original Simon and Rudell (1967) setup rather than a design that fully crosses S-S (spatial Stroop) and S-R (Simon proper) compatibility. Because the word meanings indicated the responses (so that word meanings and locations of correct responses were perfectly correlated), they cannot be analyzed separately from response locations.
} 
(RT) and percent accuracy. In order to measure sequential adjustments in Simon task performance, we not only included the factor compatibility of the current trial as is usually done, but we also added the factor "compatibility of the previous trial." Standard conflict adaptation - that is, the modulation of the compatibility effect as a function of previous-trial compatibility (cf. Fig. 1a) — should yield an interaction effect between current and previous trial compatibility (Egner, 2007; Gratton et al., 1992). To analyze direct effects of the ATD manipulation on conflict adaptation, intervention (baseline vs. low-dose vs. high-dose ATD) was added as a within-subjects factor. The effect of mood state on conflict adaptation, for the low-dose ATD and high-dose ATD sessions separately, was analyzed by using mood scores (measured at $+6.5 \mathrm{hr}$ ) as a covariate. Additionally, we also ran separate ANOVAs in which we included the binary between-subjects factors ongoing treatment (SSRI vs. SNRI) and mood response (absence vs. presence of depressed mood increase from $\mathrm{t}-1$ to $\mathrm{t}+6.5$ in the high-dose ATD session).

To visualize the hypothesized association between mood and conflict adaptation, we calculated standard individual conflict-adaptation scores by subtracting the interference effect following a correct conflict (incompatible) trial from the interference effect following a correct nonconflict (compatible) trial (cf. Fig. 1a). Before averaging sequential conditions for each individual, the first trial of each block, trials following an error, and trials with RTs not fitting the outlier

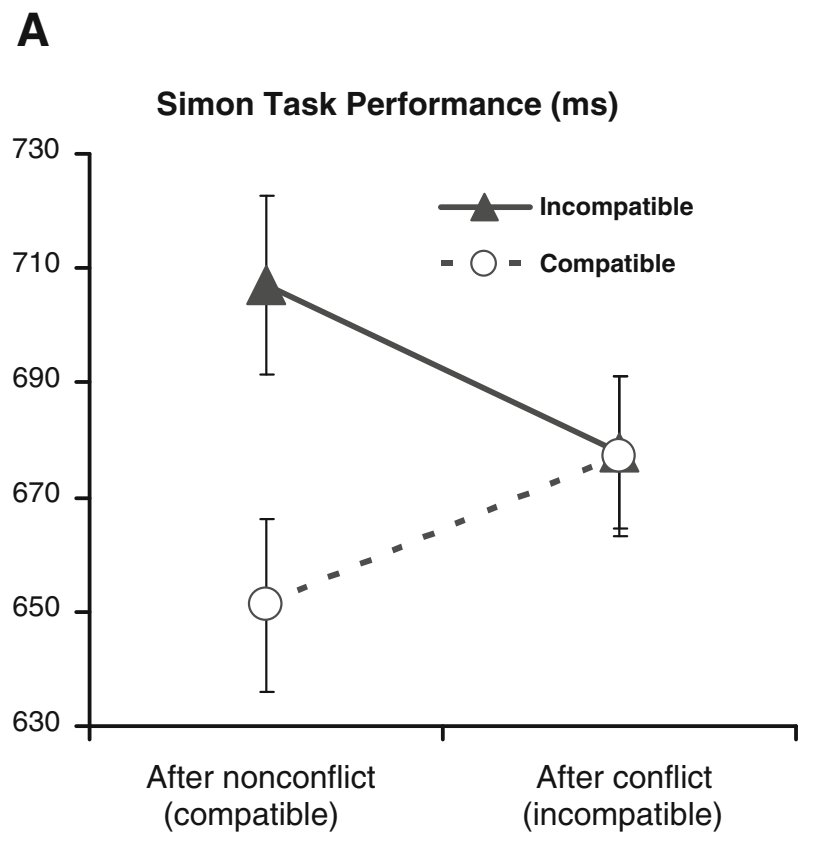

Fig. 1 a Conflict adaptation in the Simon task as evidenced by a reduced compatibility effect after conflict trials versus nonconflict trials. Graphs shows mean reaction times (in milliseconds) and criterion (deviating more than 2.5 SDs from the individual condition-specific mean) were excluded from analyses.

\section{Results}

As described in detail elsewhere (Booij et al., 2005b), highdose ATD but not low-dose ATD led to a both statistically and clinically significant induction of depressive symptoms as measured by MADRS scores $6.5 \mathrm{hr}$ after depletion $[7.9 \pm 7.8$ vs. $3.7 \pm 3.8$, mean \pm standard deviation; $t(18)$ $=3.34, p<.005]$. Behavorial data from the Simon task are presented in Table 1. The Simon task produced a standard interference effect: Incompatible trials produced longer RTs than compatible trials, $F(1,18)=23.47, p<$ $.001, M S E=1933.65$. The analysis also revealed a robust conflict-adaptation effect as indicated by an interaction between current- and previous-trial compatibility, $F(1,18)=$ 38.27, $p<.001, M S E=1143.45$. As Fig. 1a shows, the interference effect was eliminated after conflict (incompatible) trials but not after nonconflict (compatible) trials, indicating standard conflict adaptation-that is, reduced interference after conflict trials. This reduction in interference was driven by both postconflict speeding of incompatible trials [illustrating that increased conflict-driven control reduces interference; $t(18)=-4.2, p<.001]$ and by postconflict slowing of compatible trials [illustrating that

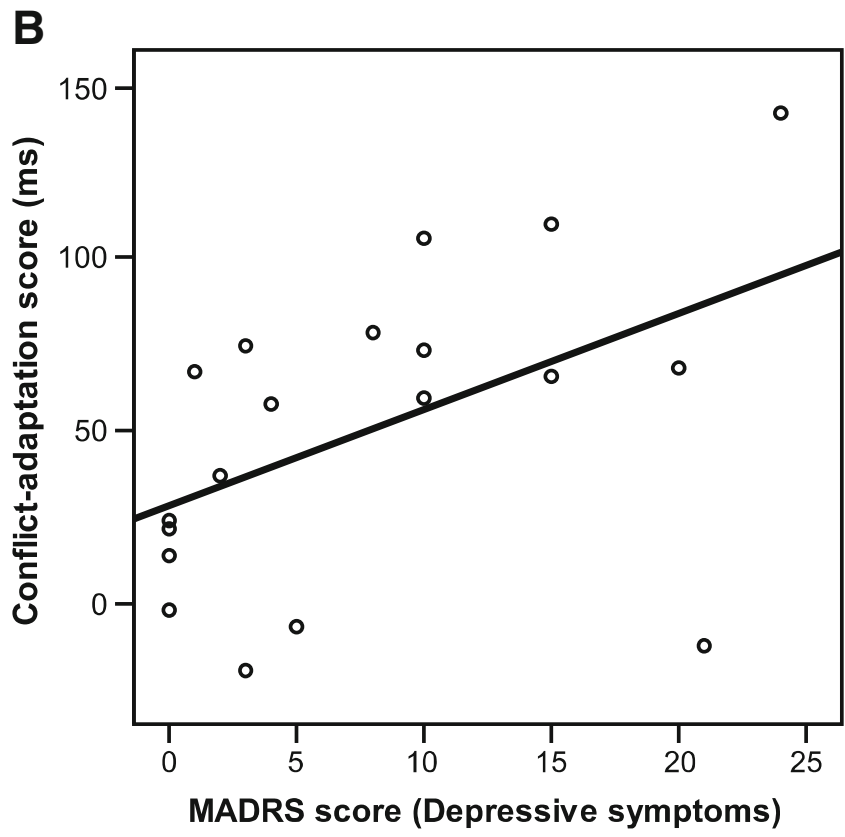

standard errors. b More depressive symptoms (MADRS score) after the high-dose ATD intervention are associated with increased conflict adaptation 
Table 1 Behavioral data for all sessions and conditions

\begin{tabular}{|c|c|c|c|c|}
\hline & \multicolumn{2}{|c|}{$\begin{array}{l}\text { Reaction time } \\
\text { (in milliseconds) }\end{array}$} & \multicolumn{2}{|c|}{$\begin{array}{l}\text { Error rate } \\
\text { (in percentages) }\end{array}$} \\
\hline & M & SE & M & SE \\
\hline \multicolumn{5}{|l|}{ Baseline } \\
\hline $\begin{array}{l}\text { Compatible trial following } \\
\text { a compatible trial }\end{array}$ & 655 & 14.4 & 0.6 & 0.3 \\
\hline $\begin{array}{l}\text { Incompatible trial following } \\
\text { a compatible trial }\end{array}$ & 705 & 12.3 & 3.6 & 1.2 \\
\hline $\begin{array}{l}\text { Compatible trial following } \\
\text { an incompatible trial }\end{array}$ & 676 & 12.1 & 0.9 & 0.4 \\
\hline $\begin{array}{l}\text { Incompatible trial following } \\
\text { an incompatible trial }\end{array}$ & 675 & 11.6 & 1.0 & 0.5 \\
\hline \multicolumn{5}{|l|}{ Low-dose session } \\
\hline $\begin{array}{l}\text { Compatible trial following } \\
\text { a compatible trial }\end{array}$ & 650 & 16.8 & 1.4 & 0.9 \\
\hline $\begin{array}{l}\text { Incompatible trial following } \\
\text { a compatible trial }\end{array}$ & 706 & 18.2 & 2.9 & 1.0 \\
\hline $\begin{array}{l}\text { Compatible trial following } \\
\text { an incompatible trial }\end{array}$ & 688 & 16.7 & 0.9 & 0.9 \\
\hline $\begin{array}{l}\text { Incompatible trial following } \\
\text { an incompatible trial }\end{array}$ & 680 & 14.4 & 0.8 & 0.8 \\
\hline \multicolumn{5}{|l|}{ High-dose session } \\
\hline $\begin{array}{l}\text { Compatible trial following } \\
\text { a compatible trial }\end{array}$ & 649 & 18.3 & 1.4 & 0.8 \\
\hline $\begin{array}{l}\text { Incompatible trial following } \\
\text { a compatible trial }\end{array}$ & 711 & 19.9 & 2.3 & 0.9 \\
\hline $\begin{array}{l}\text { Compatible trial following } \\
\text { an incompatible trial }\end{array}$ & 667 & 17.3 & 0.9 & 0.5 \\
\hline $\begin{array}{l}\text { Incompatible trial following } \\
\text { an incompatible trial }\end{array}$ & 678 & 16.4 & 1.1 & 0.8 \\
\hline
\end{tabular}

increased conflict-driven control reduces facilitation; $\mathrm{t}$ $(18)=4.5, \mathrm{p}<.001]$. Although participants made only a few errors in general, error rate analyses still showed standard interference, $F(1,18)=5.38, p<.05, M S E=0.001$, and conflict adaptation, $F(1,18)=6.30, p<.05, M S E=0.001$, effects. In addition, they revealed a main effect of previous compatibility, $F(1,18)=4.46, p<.05, M S E=.002$, indicating improved accuracy after conflict. Notably, no main effects or interactions with congruency or conflict adaptation in RT or accuracy were observed for ATD intervention. Thus, ATD did not have an effect on interference (as reported earlier by Booij et al., 2005b), and it also did not directly modulate conflict adaptation. Ongoing treatment did not have main or interactive effects.

An ANCOVA using mood score as a covariate confirmed our hypothesis: Depressed-mood scores during the high-dose ATD condition predicted increased conflict adaptation in RT as indicated by a significant three-way interaction between mood, current-trial compatibility, and previous-trial compatibility, $F(1,17)=5.30, p<.05, M S E=396.75$. As Fig. 1 shows, individuals with more depressive symptoms after the ATD intervention showed more conflict adaptation in the
Simon task. As is typically observed (Chepenik et al., 2007; van Steenbergen et al., 2010), mood did not have effects on interference or overall RT. ${ }^{2}$ Moreover, no mood effects were found for accuracy, thus showing that the effect on conflict adaptation could not be attributed to a speed-accuracy tradeoff. Because the low-dose ATD session did not lead to any mood changes (Booij et al., 2005b), data from this session were used for a control analysis: No association between mood and performance emerged. ${ }^{3}$

\section{Discussion}

We report the first evidence for a link between low tryptophan concentrations, depressed mood, and conflict adaptation in remitted depressed patients: Individuals with higher levels of depressive symptoms following high-dose ATD showed increased conflict adaptation. The ATD manipulation in itself exerted no direct effect on conflict adaptation. This finding is in line with predictions derived from MBM theory (Gendolla, 2000), with earlier behavioral and physiological observations from mood-induction studies in healthy populations (e.g., Gendolla, Abele, \& Krusken, 2001; Gendolla \& Krusken, 2002; van Steenbergen et al., 2010), and with neural evidence (e.g., Evers et al., 2009).

Our present study has important implications for understanding how depressive affect regulates cognitive control. In line with MBM theory (Gendolla, 2000), our data illustrate that depressed mood per se does not have motivational implications (as would be indicated by a modulation in attentional interference effects), but may facilitate increased

\footnotetext{
${ }^{2}$ We also investigated whether the association between depressed mood and conflict adaptation was different for repetition than for alternation trials. We added a factor in our ANCOVA categorizing ii and cc trials as either full repetition or alternation trials. Although trials in the alternation condition showed a lower conflict-adaptation effect than in the full-repetition condition (34 ms vs. $61 \mathrm{~ms}), F(1,17)=3.37$, $p=.084, M S E=717.11$, there was no evidence that this factor influenced the mood-driven modulation of conflict adaptation, $F(1,17)=1.15, p=.30, M S E=717.11$.

${ }^{3}$ An additional analysis on RT data including the binary factor mood response revealed a three-way interaction between mood response, current-trial compatibility, and previous-trial compatibility, $F(1,17)=$ $8.89, p<.01, M S E=794.91$, showing that participants who responded to the high-ATD session with a depressed mood showed an increased conflict-adaptation effect $(M=74 \mathrm{~ms})$ as compared with participants who did not respond to the ATD manipulation $(M=29 \mathrm{~ms})$. However, this three-way interaction was not further qualified by an effect of intervention, suggesting that the people responding to ATD may also respond stronger to conflict in general. Alternatively, the modulation of conflict adaptation may also be related to overall changes in mood state, because a separate analysis on mood scores revealed that responders reported higher depressed mood across sessions than nonresponders (MADRS score 8.1 vs. 1.6), $F(1,17)=14.63, p=.001$, $M S E=40.78$.
} 
cognitive control after a behavioral challenge. Interestingly, this effect was observed in a relatively low-demanding Simon task in which people were merely instructed to do their best (see also Brinkmann \& Gendolla, 2007), and in the context of depression scores that were mainly below the cut-off value for a depression diagnosis, but were still clinically relevant and much larger than the effect of mood inductions in healthy participants.

Note that our findings suggest that depressive symptoms as induced by ATD did not simply mimic the effect of depressive symptoms in currently depressed patients. That is, whereas MDD has been associated with reduced postconflict adaptation (Meiran et al., 2011; Pizzagalli, 2011), we observed that depressive symptoms were associated with increased conflict adaptation. How might this discrepancy be explained? MBM theory (Gendolla, 2000) has proposed that the association between mood and effort mobilization is nonlinear, because it is mediated by task difficulty appraisal. Accordingly, negative mood will facilitate demand-driven adjustments in effort only up to a certain level: If demands become perceived as too high to actively cope with, negative mood may actually trigger demand-driven disengagement (cf. Brehm \& Self, 1989). Evidence for this effect has been reported in moodinduction studies and can also be shown in dysphoric participants when they perform tasks with extremely high fixed demands (Brinkmann \& Gendolla, 2008). The findings of reduced postconflict adjustments in MDD patients (Meiran et al., 2011; Pizzagalli, 2011) also support this view. Taken collectively, these observations suggest an inverted-U relationship between depressive symptoms and conflict adaptation (see Brehm \& Self, 1989). It is an important aim for future studies to understand the generalizability of these findings and to disentangle the effects of increased negative affect and putative reduced availability of resources (e.g., due to rumination) in MDD (cf. Meiran et al., 2011). MBM theory assumes that the interaction between both factors determines the actual appraisal of the demand, which in turn modulates effort mobilization. This hypothesis is now ripe for further testing in other studies using sequential analyses of conflict-task performance.

At the neural level, the joint impact of depressed mood and demand evaluation on subsequent effort mobilization and cognitive control may be associated with (hyper)activation of the anterior cingulate cortex (ACC), a region important for signaling the need for more cognitive effort to the dorsolateral prefrontal cortex (DLPFC) (Botvinick et al., 2001; Davidson, Pizzagalli, Nitschke, \& Putnam, 2002; Olvet \& Hajcak, 2008; Pizzagalli et al., 2006). It has been suggested that dysfunction of this ACC-DLPFC circuit in unipolar depression also produces catastrophic reactions to errors (for a review, see Pizzagalli, 2011). Further study is needed to understand the exact neuromodulating role that 5-HT may play in this affective regulation (cf. Jocham \& Ullsperger, 2009). Future studies that combine neuroimaging methods with effort-related physiological and behavioral measures will advance our understanding of the functional role of the ACC in the affective (dys)regulation of adaptive control to fluctuating task demands.

Author note We thank Freddy van der Veen for helpful discussions. This research was supported by a grant from the Netherlands Organization for Scientific Research to G. P. H. B. and NWO-MW Grant 90457-132 and NWO-VICI Grant 453-06-005 to A. J. W. v. d. D. and L. B. is supported by a chercheur-boursier career award of the Fonds de la Recherche en Santé du Québec (FRSQ).

Open Access This article is distributed under the terms of the Creative Commons Attribution Noncommercial License which permits any noncommercial use, distribution, and reproduction in any medium, provided the original author(s) and source are credited.

\section{References}

Ach, N. (1935). Analyse des Willens [Analysis of the will]. In E. Abderhalden (Ed.), Handbuch der biologischen Arbeitsmethoden (Vol. VI). Berlin, Germany: Urban \& Schwarzenberg.

Andrews, P. W., \& Thomson, J. A. (2009). The bright side of being blue: Depression as an adaptation for analyzing complex problems. Psychological Review, 116, 620-654.

Beck, A. T. (1976). Cognitive therapy and the emotional disorders. New York, NY: International Universities Press.

Booij, L., van der Does, A. J. W., \& Riedel, W. J. (2003). Monoamine depletion in psychiatric and healthy populations: Review. Molecular Psychiatry, 8, 951-973.

Booij, L., van der Does, A. J. W., Haffmans, P. M. J., \& Riedel, W. J. (2005a). Acute tryptophan depletion in depressed patients treated with a selective serotonin-noradrenalin reuptake inhibitor: Augmentation of antidepressant response? Journal of Affective Disorders, $86,305-311$

Booij, L., van der Does, A. J. W., Haffmans, P. M. J., Riedel, W. J., Fekkes, D., \& Blom, M. J. B. (2005b). The effects of high-dose and low-dose tryptophan depletion on mood and cognitive functions of remitted depressed patients. Journal of Psychopharmacology, 19, 267-275.

Booij, L., van der Does, A. J. W., Spinhoven, P., \& McNally, R. J. (2005c). Acute tryptophan depletion as a model of depressive relapse: Behavioural specificity and ethical considerations. The British Journal of Psychiatry, 187, 148-154.

Botvinick, M. M., Braver, T. S., Barch, D. M., Carter, C. S., \& Cohen, J. D. (2001). Conflict monitoring and cognitive control. Psychological Review, 108, 624-652.

Brehm, J. W., \& Self, E. A. (1989). The intensity of motivation. Annual Review of Psychology, 40, 109-131.

Brinkmann, K., \& Gendolla, G. H. E. (2007). Dysphoria and mobilization of mental effort: Effects on cardiovascular reactivity. Motivation and Emotion, 31, 71-82.

Brinkmann, K., \& Gendolla, G. H. E. (2008). Does depression interfere with effort mobilization? Effects of dysphoria and task difficulty on cardiovascular response. Journal of Personality and Social Psychology, 94, 146-157.

Chepenik, L. G., Cornew, L. A., \& Farah, M. J. (2007). The influence of sad mood on cognition. Emotion, 7, 802-811.

Cools, R., Roberts, A. C., \& Robbins, T. W. (2008). Serotoninergic regulation of emotional and behavioural control processes. Trends in Cognitive Sciences, 12, 31-40. 
Davidson, R. J., Pizzagalli, D., Nitschke, J. B., \& Putnam, K. (2002). Depression: Perspectives from affective neuroscience. Annual Review of Psychology, 53, 545-574.

Egner, T. (2007). Congruency sequence effects and cognitive control. Cognitive, Affective, \& Behavioral Neuroscience, 7, 380-390.

Evers, E. A. T., van der Veen, F. M., Fekkes, D., \& Jolles, J. (2007). Serotonin and cognitive flexibility: Neuroimaging studies into the effect of acute tryptophan depletion in healthy volunteers. Current Medicinal Chemistry, 14, 2989-2995.

Evers, E. A. T., van der Veen, F. M., Jolles, J., Deutz, N. E. P., \& Schmitt, J. A. J. (2009). The effect of acute tryptophan depletion on performance and the BOLD response during a Stroop task in healthy first-degree relatives of patients with unipolar depression. Psychiatry Research: NeuroImaging, 173, 52-58.

Fekkes, D., Vandalen, A., Edelman, M., \& Voskuilen, A. (1995). Validation of the determination of amino-acids in plasma by high-performance liquid-chromatography using automated precolumn derivatization with O-phthaldialdehyde. Journal of Chromatography. B, Biomedical Applications, 669, 177186.

First, M. B., Spitzer, R. L., Gibbon, M., \& Williams, J. B. W. (2005). Structured clinical interview for DSM-IV Axis I Disorders, Patient edition (SCIDI/P). New York, NY: Biometrics Research Department, NYSPI.

Frank, E., Prien, R. F., Jarrett, R. B., Keller, M. B., Kupfer, D. J., Lavori, P. W., et al. (1991). Conceptualization and rationale for consensus definitions of terms in major depressive disorder: Remission, recovery, relapse, and recurrence. Archives of General Psychiatry, 48, 851-855.

Fusar-Poli, P., Allen, P., McGuire, P., Placentino, A., Cortesi, M., \& Perez, J. (2006). Neuroimaging and electrophysiological studies of the effects of acute tryptophan depletion: A systematic review of the literature. Psychopharmacology, 188, 131-143.

Gendolla, G. H. E. (2000). On the impact of mood on behavior: An integrative theory and a review. Review of General Psychology, 4, 378-408.

Gendolla, G. H., Abele, A. E., \& Krusken, J. (2001). The informational impact of mood on effort mobilization: A study of cardiovascular and electrodermal responses. Emotion, 1, 12-24.

Gendolla, G. H. E., \& Brinkmann, K. (2005). The role of mood states in self-regulation: Effects on action preferences and resource mobilization. European Psychologist, 10, 187-198.

Gendolla, G. H. E., \& Krusken, J. (2002). The joint effect of informational mood impact and performance-contingent consequences on effort-related cardiovascular response. Journal of Personality and Social Psychology, 83, 271-283.

Gratton, G., Coles, M. G. H., \& Donchin, E. (1992). Optimizing the use of information: Strategic control of activation of responses. Journal of Experimental Psychology. General, 121, 480-506.

Hamilton, M. (1960). A rating scale for depression. Journal of Neurology, Neurosurgery, and Psychiatry, 23, 56-62.

Hillgruber, A. (1912). Fortlaufende Arbeit und Willensbetätigung [Continuous work and will performance]. Untersuchungen zur Psychologie und Philosophie, 1.

Holmes, A. J., Bogdan, R., \& Pizzagalli, D. A. (2010). Serotonin transporter genotype and action monitoring dysfunction: A possible substrate underlying increased vulnerability to depression. Neuropsychopharmacology, 35, 1186-1197.

Holmes, A. J., \& Pizzagalli, D. A. (2007). Task feedback effects on conflict monitoring and executive control: Relationship to subclinical measures of depression. Emotion, 7, 68-76.

Jocham, G., \& Ullsperger, M. (2009). Neuropharmacology of performance monitoring. Neuroscience and Biobehavioral Reviews, 33, 48-60.
Kerns, J. G., Cohen, J. D., MacDonald, A. W., Cho, R. Y., Stenger, V. A., \& Carter, C. S. (2004). Anterior cingulate conflict monitoring and adjustments in control. Science, 303, 1023-1026.

Levin, R. L., Heller, W., Mohanty, A., Herrington, J. D., \& Miller, G. A. (2007). Cognitive deficits in depression and functional specificity of regional brain activity. Cognitive Therapy and Research, 31, 211-233.

Mayberg, H. S., Liotti, M., Brannan, S. K., McGinnis, S., Mahurin, R. K., Jerabek, P. A., et al. (1999). Reciprocal limbic-cortical function and negative mood: Converging PET findings in depression and normal sadness. The American Journal of Psychiatry, 156, 675-682.

Meiran, N., Diamond, G. R., Todor, D., \& Nemets, B. (2011). Cognitive rigidity in unipolar depression and obsessive compulsive disorder: Examination of task switching, Stroop, working memory updating and post-conflict adaptation. Psychiatry Research, 185, 149-156.

Mendelsohn, D., Riedel, W. J., \& Sambeth, A. (2009). Effects of acute tryptophan depletion on memory, attention and executive functions: A systematic review. Neuroscience and Biobehavioral Reviews, 33, 926-952.

Montgomery, S. A., \& Asberg, M. (1979). New depression scale designed to be sensitive to change. The British Journal of Psychiatry, 134, 382-389.

Nolen-Hoeksema, S., Wisco, B. E., \& Lyubomirsky, S. (2008). Rethinking rumination. Perspectives on Psychological Science, 3, 400-424.

Olvet, D. M., \& Hajcak, G. (2008). The error-related negativity (ERN) and psychopathology: Toward an endophenotype. Clinical Psychology Review, 28, 1343-1354.

Osinsky, R., Schmitz, A., Alexander, N., Kuepper, Y., Kozyra, E., \& Hennig, J. (2009). TPH2 gene variation and conflict processing in a cognitive and an emotional Stroop task. Behavioural Brain Research, 198, 404-410.

Philippot, P., \& Brutoux, F. (2008). Induced rumination dampens executive processes in dysphoric young adults. Journal of Behavior Therapy and Experimental Psychiatry, 39, 219-227.

Pizzagalli, D. A. (2011). Frontocingulate dysfunction in depression: Toward biomarkers of treatment response. Neuropsychopharmacology, 36, 183-206.

Pizzagalli, D. A., Peccoralo, L. A., Davidson, R. J., \& Cohen, J. D. (2006). Resting anterior cingulate activity and abnormal responses to errors in subjects with elevated depressive symptoms: A 128channel EEG study. Human Brain Mapping, 27, 185-201.

Rogers, M. A., Kasai, K., Koji, M., Fukuda, R., Iwanami, A., Nakagome, K., et al. (2004). Executive and prefrontal dysfunction in unipolar depression: A review of neuropsychological and imaging evidence. Neuroscience Research, 50, 1-11.

Ruhe, H. G., Mason, N. S., \& Schene, A. H. (2007). Mood is indirectly related to serotonin, norepinephrine and dopamine levels in humans: A meta-analysis of monoamine depletion studies. Molecular Psychiatry, 12, 331-359.

Schmitt, J. A. J., Jorissen, B. L., Sobczak, S., van Boxtel, M. P. J., Hogervorst, E., Deutz, N. E. P., et al. (2000). Tryptophan depletion impairs memory consolidation but improves focussed attention in healthy young volunteers. Journal of Psychopharmacology, 14, $21-$ 29.

Simon, J. R., \& Rudell, A. P. (1967). Auditory S-R compatibility: Effect of an irrelevant cue on information processing. Journal of Applied Psychology, 51, 300-304.

van der Does, A. J. W. (2001). The effects of tryptophan depletion on mood and psychiatric symptoms. Journal of Affective Disorders, 64, 107-119.

van Steenbergen, H., Band, G. P. H., \& Hommel, B. (2010). In the mood for adaptation: How affect regulates conflict-driven control. Psychological Science, 21, 1629-1634. 